\title{
METRÓPOLE CHINESA INTELIGENTE DE SHENZHEN: LIÇÕES PARA MOBILIDADE URBANA
}

Verônica Nascimento Brito Antunes ${ }^{1}$ Jacilene dos Santos Silva² Camila do Carmo Hermida ${ }^{3}$

Resumo: O artigo pretende examinar os principais aspectos da infraestrutura e do arcabouço institucional que contribuíram para cidade a chinesa de Shenzhen se tornar a primeira metrópole do mundo a operar com frota de ônibus $100 \%$ elétrica. 0 procedimento metodológico adotado na pesquisa consiste em levantamento e seleção bibliográfica - para caracterização do estudo de caso e identificação da estrutura de incentivos que impactou na mobilidade urbana e viabilizou as transformações da frota de ônibus na cidade. Os resultados da pesquisa confirmam que os investimentos estrangeiros diretos associados às políticas públicas nacionais e locais estimularam de forma significativa a transição para um sistema de mobilidade elétrica em Shenzhen.

Palavras-chave: Cidades inteligentes. Mobilidade urbana. Frota de ônibus elétrica. Shenzhen.

\section{THE SMART CHINESE CITY OF SHENZHEN: LESSONS FOR URBAN MOBILITY}

Abstract: The article intends to examine the main aspects of infrastructure and the institutional framework that contributed to the Chinese city of Shenzhen becoming the first metropolis in the world to operate with a $100 \%$ electric bus fleet. The methodological procedure adopted in the research consists of survey and bibliographic selection - to characterize the case study and identify the structure of incentives that impacted urban mobility and enabled the transformation of the bus fleet in the city. The survey results confirm that foreign direct investments associated with national and local public policies have significantly stimulated the transition to an electric mobility system in Shenzhen.

Keywords: Smart cities. Urban mobility. Electric bus fleet. Shenzhen.

\section{METRÓPOLIS CHINA INTELIGENTE DE SHENZHEN: LECCIONES PARA LA MOVILIDAD URBANA}

Resumen: El artículo pretende examinar los principales aspectos de la infraestructura y el marco institucional que contribuyeron a que la ciudad chino Shenzhen se convirtiera en la primera metrópoli del mundo en operar con una flota de autobuses $100 \%$ eléctrica. El procedimiento metodológico adoptado en la investigación consiste en el relevamiento y la selección bibliográfica - para caracterizar el caso de estudio y identificar la estructura de incentivos que impactó la movilidad urbana y permitiera la transformación de la flota de buses en la ciudad. Los resultados de la encuesta confirman que las inversiones extranjeras directas

\footnotetext{
1 Universidade Federal de Alagoas, Programa de Pós-graduação em Economia Aplicada, Maceió, Brasil, veronica.antunes@feac.ufal.br, https://orcid.org/0000-0003-2273-7460.

2 Mestre em Economia Aplicada pela Universidade Federal de Alagoas. E-mail: ja_cilene@hotmail.com, https://orcid.org/0000-0003-2467-1899.

3 Universidade Federal de Alagoas, Programa de Pós-graduação em Economia Aplicada, Maceió, Brasil, camila.hermida@feac.ufal.br, https://orcid.org/0000-0002-7206-5132.
} 
asociadas con las políticas públicas nacionales y locales han estimulado significativamente la transición a un sistema de movilidad eléctrica en Shenzhen.

Palabras clave: Ciudades inteligentes. Mobilidad urbana. Flota de autobuses eléctricos. Shenzhen.

\section{Introdução}

Embora historicamente a nação chinesa tenha o carvão mineral como principal recurso, nos últimos anos o país tem expandido sua demanda, fazendo uso de outras fontes de energia, buscando ampliar de forma gradual o uso de renováveis (eólica, solar, hidráulica). Entretanto, mesmo possuindo vários recursos naturais, a importação de commodities energéticas é alta e cresce em conjunto com sua economia (FERREIRA et al., 2014).

A China é o país que mais polui no mundo, e também é reconhecido como o que mais investe em recursos renováveis; registrou níveis 45 vezes maiores do que o limite diário de poluentes considerado aceitável pela Organização Mundial da Saúde (OMS). Nos últimos anos, o país tem conseguido diminuir significativamente essas taxas (PNUMA, 2019).

A transição energética da China, bem como o desenvolvimento de uma política externa mais ativa nas Convenções do Clima são gradativas, assim como as iniciativas voltadas a práticas mais sustentáveis no que diz respeito a mobilidade urbana. No ano de 2012, o governo chinês deu início ao Programa de Desenvolvimento Nacional de cidades inteligentes buscando estimular a utilização de recursos de alta tecnologia na gestão do espaço urbano. Shenzhen é um grande exemplo de metrópole inteligente, servindo de modelo de desenvolvimento com forte atuação de tecnologias avançadas e sustentabilidade. Ressalte-se que foi a primeira metrópole a operar com uma frota de ônibus 100\% movida a energia elétrica mundialmente.

O presente artigo tem por objetivo examinar os principais aspectos da infraestrutura e arcabouço institucional que, possivelmente funcionaram como uma estrutura de incentivos e, contribuíram para Shenzhen se tornar a primeira metrópole do mundo a operar com frota de ônibus $100 \%$ elétrica.

Para consecução do objetivo proposto, a pesquisa cumpre fins exploratórios e analíticos. O procedimento metodológico adotado neste trabalho apresenta as seguintes etapas: i) levantamento e seleção bibliográfica - para caracterização do estudo de caso, e concepção de Shenzhen como cidade inteligente; ii) identificação da estrutura de incentivos (programas, políticas, investimentos e demais ações) que 
impactaram na mobilidade urbana e viabilizaram as transformações da frota de ônibus na metrópole.

\section{Cidades Inteligentes}

De acordo com Dameri e Cocchia (2013) a definição de "cidade inteligente" surgiu no ano de 1994 e reflete um modelo de cidade onde a interação entre a população, o sistema econômico e as instituições são alteradas. Isto é, onde as mudanças nas dimensões sociais são priorizadas para o entendimento das dinâmicas dentro desse processo. Nesse contexto as inovações tecnológicas são tidas como uma importante fonte que favorecem as modificações nas cidades (AIETA, 2016).

Segundo Rossatto (2015) a expressão "smart city" ou "cidade inteligente" traduz essencialmente o nível tecnológico empregado para favorecer o cotidiano da população, para além do conceito usado nos anos 1990, na qual era realizada descrições acerca de cidades digitais, quando os ambientes urbanos davam início a aquisição das inovações tecnológicas.

Todavia é importante ressaltar que as cidades desde os primórdios enfrentam dificuldades em sua organização, estrutura urbana, principalmente no que se refere aos impactos ambientais. Atualmente de acordo com alguns autores como Accenture (2014) entre outros, uma cidade inteligente é aquela que faz uso das inovações tecnológicas para beneficiar a vida dos indivíduos, realizando de modo mais proveitoso os serviços urbanos de maneira eficiente, assim melhorando a qualidade de vida da população e modificando a ligação que envolve instituições locais, empresas e indivíduos.

Em linhas gerais, uma "cidade inteligente" é aquela que opera com tecnologias avançadas para a administração do sistema urbano: big data como ferramenta para identificar os problemas da cidade, informações na nuvem com atualizações em tempo real, sistemas integrados de informação. Isso contextualizado de maneira local, sujeito a eventuais transformações que surgem nessa esfera (ROSSATTO, 2015).

Cunha et al. (2016) apresentam quatro elementos em comum presentes nas mais diversas definições: visão holística ou global, um meio para melhorar a qualidade de vida, a tecnologia como fator disruptivo e um novo modelo de relações. Além disso, ressalta o elemento ser sustentável presente nos países emergentes e 
em desenvolvimento. A Figura 1 mostra os elementos comuns nas definições de cidade inteligente.

Figura 1 - Elementos Comuns nas definições de smart city

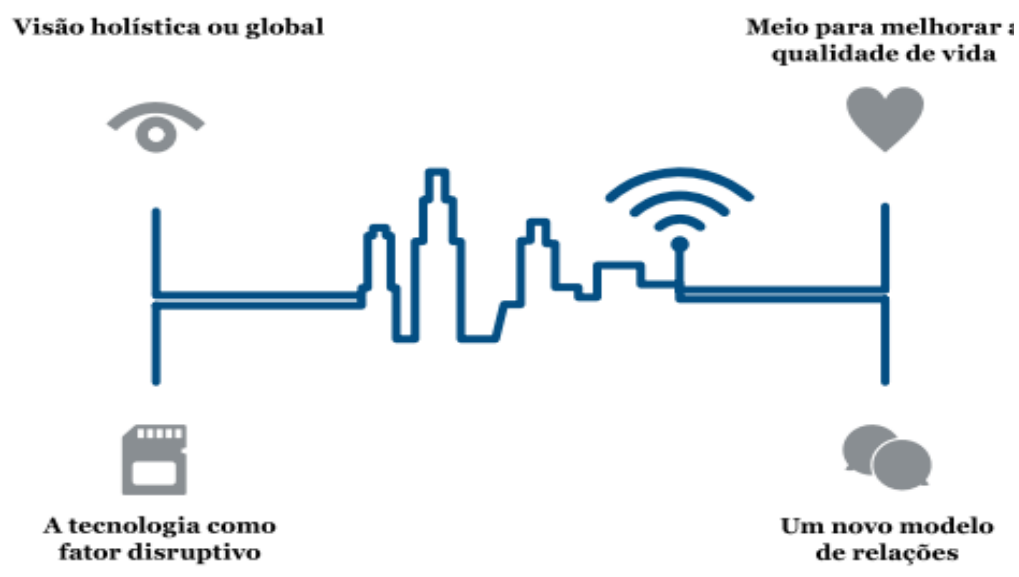

Fonte: CUNHA et al. (2016, p. 29).

De acordo com Planet Smart city (2018), a China é o país que possui o maior número de cidades inteligentes do mundo, detendo cerca de 500 projetos piloto. Esses projetos começaram no ano de 2012 quando o governo chinês deu início ao programa de desenvolvimento nacional de cidades inteligentes buscando estimular a utilização de inovações tecnológicas mais atuais (inteligência artificial, internet das coisas, dentre outras), a fim de favorecer o fluxo de tráfego, aperfeiçoar o emprego e transformar, em termos energéticos, os prédios públicos mais eficientes. A cidade de Shenzhen é um grande exemplo de smart city servindo de modelo de desenvolvimento com forte atuação de tecnologias avançadas e sustentabilidade.

\section{Shenzhen}

Localizada ao longo da Costa Sul da China, fora promovida a condição de cidade no final da década de 1970, período em que o governo implantou uma política de reforma e abertura criando as Zonas Econômicas Especiais (ZEEs) no país. Visto que havia uma crescente lacuna de desenvolvimento entre as regiões leste e oeste e, dada a sua localização próxima a Hong Kong, Shenzhen foi escolhida para iniciar esse processo de abertura ao investimento estrangeiro direto (LONGFELLOW, 2017).

Como a primeira ZEE da China, a cidade estimulou o crescimento econômico após o quase colapso da economia socialista de planejamento central em 1980. O desenvolvimento da economia de mercado socialista em Shenzhen pode ser dividido 
em três fases: fase de construção de 1980 a 1985; reestruturação econômica de 1986 ao início dos anos 1990; e fase de reengenharia desde meados da década de 1990 (NG, 2003). A figura 2 mostra os distritos da cidade.

Figura 2 - Distritos em Shenzhen

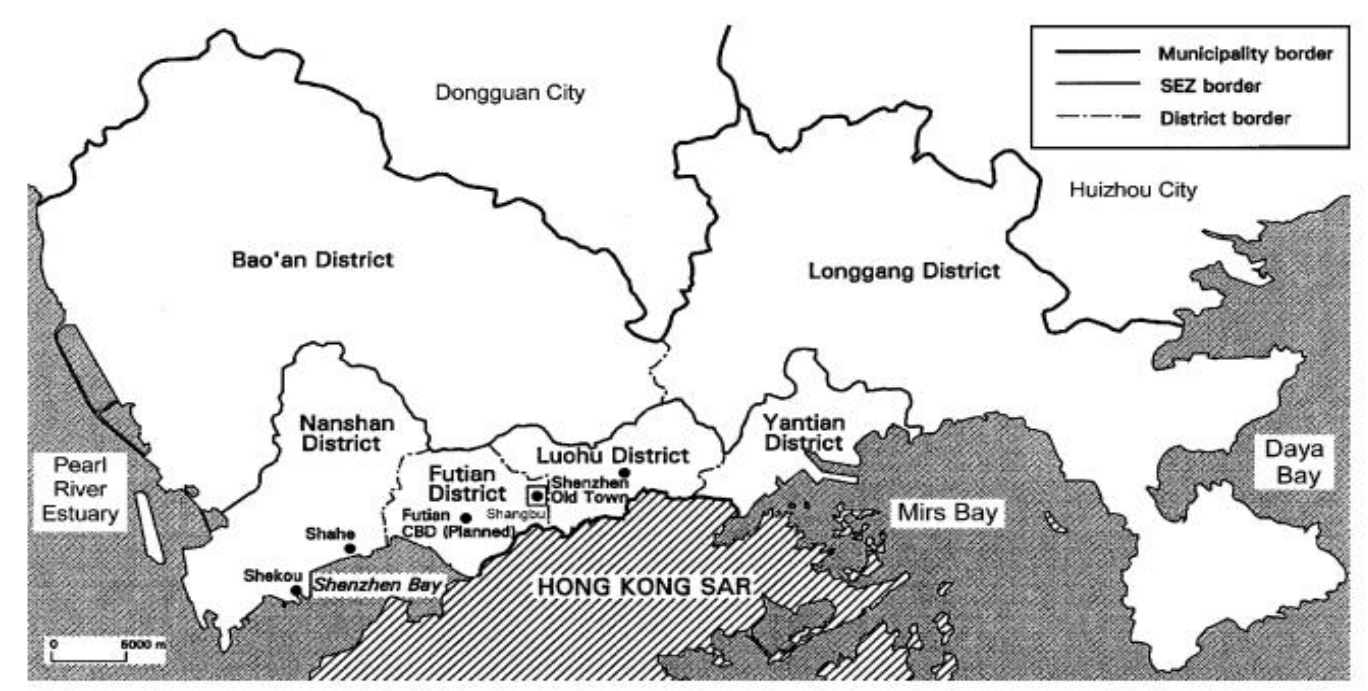

Fonte: NG (2003, p. 430).

Conforme estatística para o ano de 2017 Shenzhen reúne mais de 12 milhões de habitantes, em uma área de aproximadamente dois mil quilômetros quadrados, localizada na região metropolitana do Delta do Rio das Pérolas (LONGFELLOW, 2017). É um importante centro financeiro e de manufatura, e abriga algumas das maiores companhias de tecnologia chinesa. Grandes empresas que utilizam tecnologia avançada fabricam seus produtos eletrônicos na cidade e pequenas startups buscam comercializar seus produtos no mercado rapidamente, com o mais baixo custo possível para os consumidores. É importante salientar que a infraestrutura da cidade é extremamente desenvolvida, o que possibilita a comercialização dada a facilidade de entrega dos produtos. A figura 3 mostra uma imagem noturna da cidade. 
Figura 3 - Shenzhen

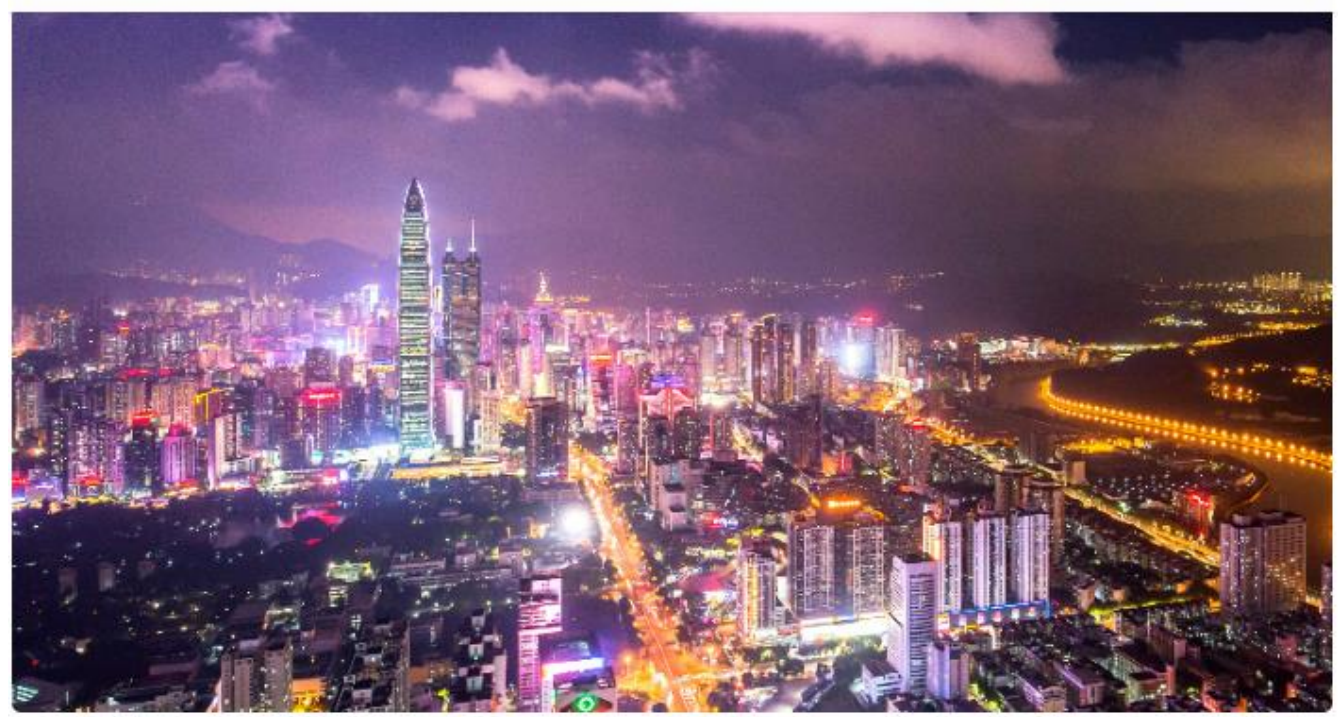

Fonte: LONGFELLOW (2017).

\section{Mobilidade urbana e a indústria de veículos elétricos}

O país concentra o maior mercado automobilístico do mundo e desde o ano de 2005 a expansão da frota de veículos chineses é equivalente a 15,1\%a.a. (ZOTIN, 2018). Com o país assumindo uma posição atrasada, no que diz respeito a tecnologias-chave de veículos de combustão interna, frente a outras nações, os líderes chineses adotaram como estratégia fomentar a indústria de veículos de nova energia (NEVs), propagando-a paulatinamente no comércio interno. A indústria NEVs é uma prioridade por alguns governos locais e provinciais, bem como pelo governo central no desenvolvimento da cadeia de valor, assegurando investimentos estaduais significativos (ZOTIN, 2018).

Com a criação das políticas, a indústria de veículos elétricos passou a ganhar espaço, principalmente no que se refere a construção de infraestrutura de abastecimento, aumento da capacidade de produção de baterias e assistência de qualidade dos NEVs fabricados (ZOTIN, 2018). Assim, com à política para veículos elétricos buscou-se ampliar a fabricação de NEVs como também a infraestrutura de recarga para dar o suporte necessário, no qual de início a prioridade foi subsidiar os veículos elétricos a bateria e depois partir para outros NEVs (híbridos plug-in d a célula combustível).

Os problemas relacionados a emissão de gases poluentes através dos veículos com motor de combustão agravaram-se ao longo dos anos. Na China a poluição causada por PM 2.5 (partícula no ar que facilita a absorção de substâncias tóxicas pelos alvéolos pulmonares) preocupa os moradores das cidades do país. Na 
maior parte das cidades, as emissões da queima de carvão são as que provocam maiores níveis de PM 2.5. Em Shenzhen a emissão de veículos é o que mais provoca o PM 2.5, sendo responsável por 52,1\%, outras grandes cidades, como Pequim (45\%), Xanguai (29,2\%) e, Guangzhou (21,7\%) também apresentam elevado nível de PM 2.5 (LIN et al., 2019).

O governo central empregou algumas políticas com altos subsídios para incentivar a frota de ônibus elétricos e selecionou a cidade Shenzhen, no ano de 2009, como uma das 13 cidades piloto. Esse projeto foi firmado através da combinação de financiamento do governo chinês e subsídios da Comissão de Finanças do Munícipio de Shenzhen, sendo também favorecido por modelos de serviços econômicos (ELLEN MACARTHUR FOUNDATION, 2019). O quadro 1 mostra os departamentos do munícipio atuantes na implementação da transição para um sistema de mobilidade elétrica.

Quadro 1 - Equipe envolvida na transição para um sistema de mobilidade elétrica em Shenzhen.

\begin{tabular}{|c|c|}
\hline $\begin{array}{c}\text { Departamentos do Município de } \\
\text { Shenzhen }\end{array}$ & Atribuição \\
\hline $\begin{array}{l}\text { A Comissão de desenvolvimento e reforma } \\
\text { da cidade de Shenzhen }\end{array}$ & $\begin{array}{l}\text { Receber orientação do Comitê Nacional de } \\
\text { Desenvolvimento e Reforma da China e } \\
\text { coordenar a implementacão local. }\end{array}$ \\
\hline $\begin{array}{llll}\text { A Comissão } & \text { de } & \text { Recursos, Solo } & \text { e } \\
\text { Planejamento } & \text { Urbano da cidade de } \\
\text { Shenzhen }\end{array}$ & $\begin{array}{l}\text { Identificar terras adequadas desenvolvidas e } \\
\text { subdesenvolvidas e supervisiona locais de } \\
\text { estações e pontos de carregamento. }\end{array}$ \\
\hline Governo distrital & $\begin{array}{l}\text { Apoiar o fornecimento de alvarás de } \\
\text { loteamento para estações e pontos de } \\
\text { carregamento. }\end{array}$ \\
\hline $\begin{array}{l}\text { Comissão de Transporte da cidade de } \\
\text { Shenzhen }\end{array}$ & $\begin{array}{l}\text { Facilitar o deslocamento dos e-ônibus ao } \\
\text { conceder acesso preferencial nas ruas. }\end{array}$ \\
\hline
\end{tabular}

Fonte: ELLEN MACARTHUR FOUNDATION (2019): Adaptado pelas autoras.

Em 2017, Shinzhen após substituição por ônibus eletrônicos com bateria (ônibus elétricos), se tornou a primeira metrópole mundial com frota urbana totalmente elétrica. A cidade possui atualmente a maior frota de ônibus elétrico do planeta, composta por 16.359 mil e-ônibus, superando a frota de ônibus elétrico de cidades importantes, como New York, Los Angeles, New Jersey, Chicago e Toronto, juntas. A frota de ônibus elétricos é abastecida por 26 estações de recarga, sendo estações de consumo de eletricidade em grande escala. As estações de recarga, na China, a fim de evitar o congestionamento com outras cargas na rede de distribuição, estão conectadas às subestações transformadoras exclusivas (LIN et al., 2019). 
Apesar do alto custo para implantação dos ônibus elétricos, a metrópole buscou contornar a situação, como alternativas investiu em um tipo de ônibus que suporta $250 \mathrm{~km}$ de condução com uma recarga de cinco horas e ainda assegurou que a maioria das linhas de ônibus tivessem instalações de recarga (GRAY, 2018). Destarte, as quatro principais estratégias que contribuíram para que Shenzhen fosse capaz de eletrificar seus ônibus foram: os subsídios nacionais e locais, locação para diminuir os investimentos iniciais, carregamento e operações otimizados e garantia vitalícia de baterias (XUE; ZHOU, 2018).

Em Shenzhen cada ônibus elétrico roda $174 \mathrm{~km}$ por dia dentro da cidade, por cerca de 14 horas de uso, sendo realizada sua recarga e limpeza nas garagens no intervalo. A autonomia de uma carga completa é suficiente, visto que um ônibus elétrico tem a capacidade de circular $200 \mathrm{~km}$ com uma única carga (MOBILIZE BRASIL, 2018). Com a adoção dos ônibus elétricos a cidade conseguiu diminuir significativamente a poluição do município, gerando uma economia que permitiu reduzir os preços de carros e ônibus elétricos. Além disso, com o custo dos veículos elétricos mais acessíveis outras cidades chinesas (Guandong e Nanjing) podem também tornarem-se $100 \%$ elétricas, segundo o site Mobilize Brasil. A figura 4 abaixo mostra a estação de carregamento elétrico para ônibus em Shenzhen.

Figura 4 - Estação de carregamento elétrico para ônibus em Shenzhen

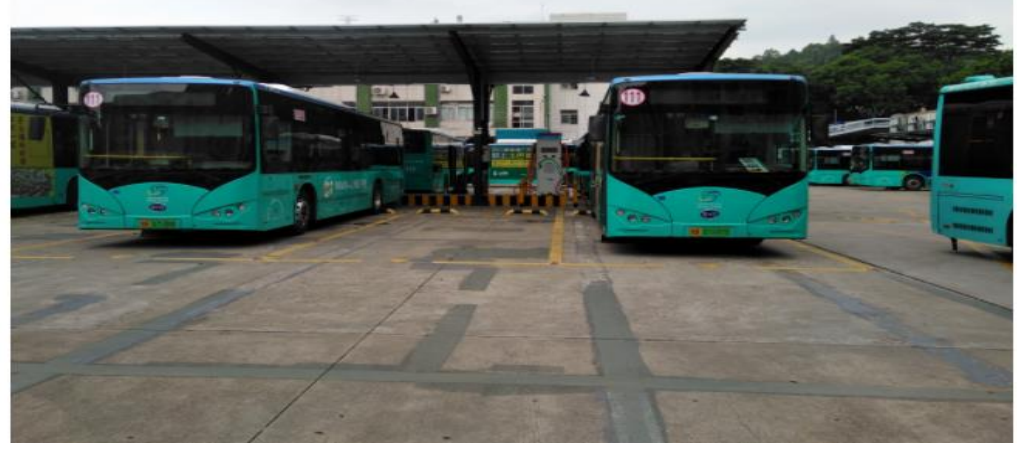

Fonte: XUE; ZHOU/WRI China (2018).

A cidade de Shenzhen também se empenhou na melhoria da infraestrutura urbana, adquirindo mais de 500 estações e 5.100 pontos de recarga de ônibus. Outro ponto importante é que o governo está dando andamento em projetos afim de expandir o programa para outros tipos de transportes, isto é, a prioridade é o setor de mobilidade de forma geral (ELLEN MACARTHUR FOUNDATION, 2019). Assim, os líderes chineses deram prioridade para a construção de infraestrutura de 
cobrança de transportes de serviços públicos, como ônibus, táxis e transportes sanitários (LIN et al., 2019). A figura 4 mostra a quantidade por tipos variados de veículos elétricos (EVs) até 2020 na China, o número de ônibus elétricos previsto é de 200 unidades. Vale ressaltar que os e-trucks correspondem aos veículos elétricos de saneamento e veículos de logística.

Figura 4 - Tipos variados de veículos elétricos até 2020 na China.

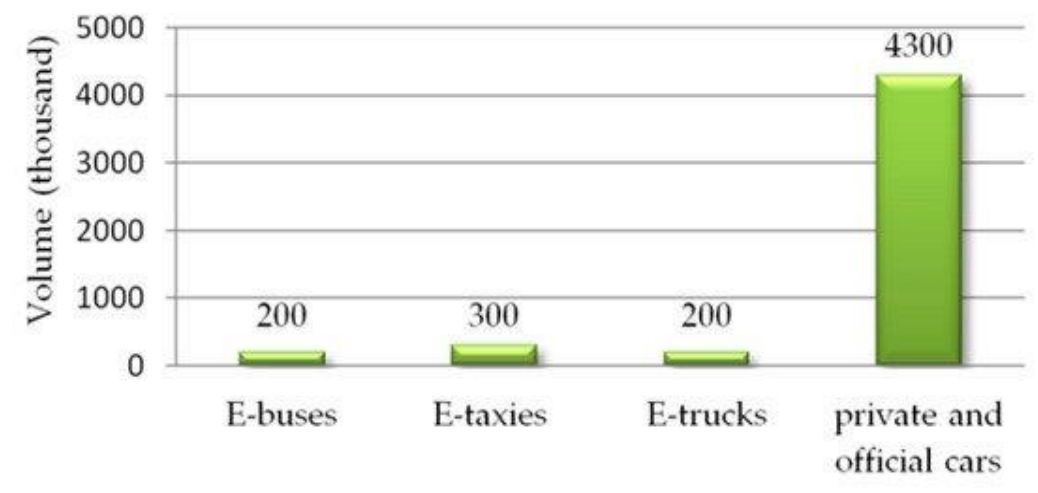

EV Types

Fonte: LIN et al. (2019, p.2).

A figura 5 apresenta o plano de implantação de recarga na China. No decorrer dos cinco anos o governo chinês planejou criar 3.850 estações de carregamento para os ônibus elétricos, a fim de incentivar a eletrificação do transporte público. A cidade já conta com mais de 12 mil táxis elétricos, o que representa cerca de 62,5\% de toda a frota.

Figura 5 - Plano de implantação de recarga na China de 2015 a 2020.

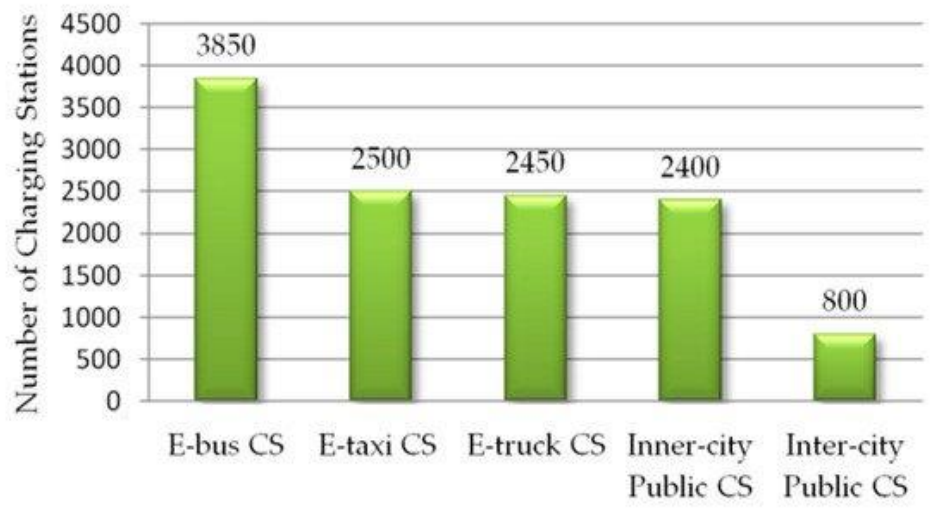

Fonte: LIN et al. (2019, p.2).

As políticas nacionais e locais estimularam de forma significativa a transição para um sistema de mobilidade elétrica em Shenzhen, sendo essa mobilidade reforçada pelo Plano de Desenvolvimento da Nova Indústria Energética de Shenzhen 2009-2015, a Política de Desenvolvimento da Nova Indústria Energética 
de Shenzhen e o 13ํㅜㄹano Quinquenal para o desenvolvimento estratégico da nova indústria (ELLEN MACARTHUR FOUNDATION, 2019).

Atualmente todos os ônibus que circulam em Shenzhen são elétricos. Segundo a Comissão de Transporte de Shenzhen o uso de ônibus eletrônicos diminui o consumo de óleo combustível em 345 mil toneladas, como também, em âmbito local, a frota de e-ônibus reduz a liberação em 1,35 milhão de toneladas de dióxido de carbono (LIN et al., 2019).

Destarte, o plano nacional de pilotos estimulou o governo chinês a investir mais no desenvolvimento da indústria de transportes elétricos, avaliada em 100 bilhões de iuanes em 2017. Empresas como a BYD (maior produtora de veículos elétricos chinês), localizada em Shenzhen, foram beneficiadas, vendendo e-ônibus para 300 cidades, em outros países, como no Japão, na Europa, EUA dentre outros (ELLEN MACARTHUR FOUNDATION, 2019).

\section{Resultados e Discussão}

Para melhor compreensão do perfil do sistema de transporte urbano por ônibus elétrico em Shenzhen, foi elaborado um quadro síntese com os principais aspectos da frota da cidade chinesa e um comparativo com a cidade de São Paulo. As duas cidades são importantes centros financeiros, econômicos, urbanos e administrativos de seus respectivos países e apresentam quantitativo populacional semelhante. $\mathrm{O}$ quadro 2 apresenta as principais características das frotas de ônibus elétricos das cidades de Shenzhen e São Paulo.

Quadro 2 - Principais características das frotas de ônibus elétricos Shenzhen e São Paulo

\begin{tabular}{|l|l|l|l|l|l|l|l|}
\hline Cidades & $\begin{array}{c}\text { População } \\
\text { (milhões) }\end{array}$ & $\begin{array}{c}\text { Área } \\
\text { (mil } \\
\text { km) }\end{array}$ & $\begin{array}{c}\text { Frota } \\
\text { (unida } \\
\text { des) }\end{array}$ & Autonomia & $\begin{array}{c}\text { Estações } \\
\text { (unidades) }\end{array}$ & $\begin{array}{c}\text { Pontos } \\
\text { de } \\
\text { recarga }\end{array}$ & $\begin{array}{c}\text { Ônibus } \\
\text { (marca- } \\
\text { modelo) }\end{array}$ \\
\hline Shenzhen & 12,53 & 2,05 & 16.359 & $250 \mathrm{~km}$ & 500 & 5.100 & BYD-variados \\
\hline $\begin{array}{l}\text { São } \\
\text { Paulo }\end{array}$ & 12,18 & 1,5 & 15 & $250 \mathrm{~km}$ & 30 & 30 & BYD - D9W \\
\hline
\end{tabular}

Fonte: Elaborado pelas autoras, 2020.

A capital paulista com o intuito de cumprir metas de redução das emissões de poluentes, integra um projeto piloto da SPTrans (2019) e possui ônibus elétricos que estão operando em linhas da zona sul da cidade. A marca chinesa BYD também está presente no Brasil, apresentando mesmo nível de autonomia. Nas duas cidades as recargas acontecem em período médio de 14 horas, com duração entre duas a quatros horas. Estima-se que cada ônibus elétrico em operação urbana reduz a 
emissão de aproximadamente 1,8 toneladas de dióxido de carbono, o que expressa a significativa melhoria da qualidade do ar e impactos positivos ao meio ambiente.

Cabe ressaltar o potencial para captação de energia renovável, em especial energia solar que vem sendo utilizada para geração de eletricidade para frota de São Paulo. O incentivo a tecnologias limpas em Shenzhen é constante, entretanto ainda é expressiva a energia gerada por termoelétricas a base de carvão. Outro aspecto importante diz respeito a capacidade da frota operar em um circuito de rede inteligente, contribuindo para o sistema integrado de geração e consumo de energia elétrica. A infraestrutura de rede e de recarga existente na capital chinesa permite que a energia armazenada nas baterias dos ônibus esteja conectada a rede elétrica de distribuição e, em determinadas circunstâncias, possa ser alocada através de tecnologias de resposta à demanda.

Ao examinar os principais elementos do arcabouço institucional que possivelmente contribuíram para o desenvolvimento de Shenzhen como cidade inteligente e as transformações de sua frota de ônibus em um período de cinco anos verificam-se (quadro 3):

Quadro 3 - Síntese dos instrumentos ações e resultados

\begin{tabular}{|c|c|c|}
\hline Instrumentos & Ações & Resultados \\
\hline $\begin{array}{l}\text { Lei da Energia } \\
\text { Renovável (2005) }\end{array}$ & $\begin{array}{l}\text { Unificação de política governamental } \\
\text { nacional para o desenvolvimento de } \\
\text { energia renovável (ER) na China. }\end{array}$ & $\begin{array}{l}\text { Definiu tarifas e metas para } \\
\text { diferentes tecnologias; } \\
\text { A indústria de ER ganha } \\
\text { efetivamente caráter de } \\
\text { projeto de Estado. }\end{array}$ \\
\hline $\begin{array}{l}\text { Plano de } \\
\text { Desenvolvimento de } \\
\text { Médio e Longo } \\
\text { Prazo para Energia } \\
\text { Renovável (2007) } \\
\end{array}$ & $\begin{array}{c}\text { Uso de políticas fiscais para estímulos a } \\
\text { ER, apoio a P\&D e a fabricação de } \\
\text { equipamentos de tecnologias de energia } \\
\text { renovável (TER). }\end{array}$ & $\begin{array}{l}\text { Difusão de tecnologias } \\
\text { relacionadas à } \\
\text { sustentabilidade; e } \\
\text { tecnologias poupadoras de } \\
\text { energia e redutoras de } \\
\text { impactos ambientais. }\end{array}$ \\
\hline $\begin{array}{l}13 \% \text { Plano } \\
\text { Quinquenal para o } \\
\text { desenvolvimento } \\
\text { estratégico da nova } \\
\text { indústria } \\
(2016-2020)\end{array}$ & $\begin{array}{l}\text { Investimentos em inovação para atingir } \\
\text { metas (2020): P\&D, } 2,5 \% \text { do PIB, e a } \\
\text { taxa de contribuição do progresso } \\
\text { científico e tecnológico para o crescimento } \\
\text { econômico chegue a } 60 \% \text {. }\end{array}$ & $\begin{array}{l}\text { Mudanças estruturais que } \\
\text { reforçam o investimento na } \\
\text { área de inovação e vem } \\
\text { repercutindo sobre a } \\
\text { mobilidade urbana. }\end{array}$ \\
\hline $\begin{array}{l}\text { Políticas de } \\
\text { incentivo ao } \\
\text { Investimento } \\
\text { estrangeiro direto }\end{array}$ & $\begin{array}{l}\text { Redesenho dos fluxos de investimentos } \\
\text { para China (mercado e como base de } \\
\text { produção para o mundo). }\end{array}$ & $\begin{array}{c}\text { Modificações nas suas } \\
\text { estratégias tecnológicas e } \\
\text { inserção nas cadeias globais } \\
\text { de valor. Especificamente } \\
\text { em Shenzhen estimulou o } \\
\text { processo de consolidação } \\
\text { das fábricas de motores } \\
\text { elétricos. }\end{array}$ \\
\hline Medidas fiscais & $\begin{array}{l}\text { Planejamento governamental nacional e } \\
\text { local com foco em subsídios às }\end{array}$ & $\begin{array}{l}\text { Antes de } 2016 \text {, um ônibus } \\
\text { eletrônico de Shenzhen } \\
\text { recebia um subsídio }\end{array}$ \\
\hline
\end{tabular}




\begin{tabular}{|c|c|c|}
\hline $\begin{array}{c}\text { específicas } \\
\text { (Subsídios) }\end{array}$ & $\begin{array}{c}\text { operadoras de ônibus e consumidores de } \\
\text { veículos elétricos. }\end{array}$ & $\begin{array}{c}\text { governamental de US\$ } \\
150.000, \text { mais da metade do } \\
\text { preço do veículo. }\end{array}$ \\
\hline $\begin{array}{c}\text { Medidas financeiras } \\
\text { (Opções de leasing) }\end{array}$ & $\begin{array}{c}\text { Parceria pública e privada para os } \\
\text { investimentos iniciais das operadoras de } \\
\text { ônibus. }\end{array}$ & $\begin{array}{c}\text { Operadores de ônibus em } \\
\text { Shenzhen alugam veículos } \\
\text { de fabricantes; Reduziu a } \\
\text { necessidade de } \\
\text { financiamento de dívidas. }\end{array}$ \\
\hline
\end{tabular}

Fonte: ZOTIN (2018) e XUE; ZHOU (2018): Adaptado pelas autoras.

O quadro 3 reúne os principais instrumentos considerados na pesquisa como decisivos para transformações ocorridas nas Zonas Econômicas Especiais da China, tal qual Shenzhen. Cabe considerar que as políticas públicas chinesas de estímulo às energias renováveis e tecnologias mais limpas englobam políticas macroeconômicas como a política fiscal, comercial e monetária. Especificamente, os investimentos diretos estrangeiros, os subsídios e as opções de leasing foram necessários às mudanças no modal ônibus urbano entre os anos de 2012 e 2017 na metrópole, tendo em vista que garantiram os recursos financeiros a expansão da frota e de sua infraestrutura.

Complementarmente, fabricantes de ônibus oferecem garantia vitalícia para veículos e baterias. Beneficiamento de licenciamento de veículos, dispensa dos VEs do custoso sistema de leilão de placas.

Em linhas gerais, por meio do planejamento governamental e das estratégias para difusão de tecnologia, inovação e conhecimento, aliados a uma tendência em assumir maiores compromissos de reduzir as emissões de poluentes, Shenzhen destaca-se como uma metrópole inteligente e apresenta ao mundo a possibilidade de mudanças a partir do seu pioneirismo.

\section{Considerações Finais}

A cidade de Shenzhen é um modelo cidade inteligente que reúne tecnologias avançadas e sustentabilidade visando melhorias na gestão do espaço e na mobilidade urbana.

Por meio do planejamento governamental, orientando as políticas públicas e os investimentos em infraestrutura, tornou-se referência em alta tecnologia em poucos anos, destacando-se como um dos principais centros financeiros, urbanos, econômicos e administrativos da China. Atualmente desponta como primeira metrópole mundial a operar com frota de ônibus urbana integralmente elétrica. 


\section{REFERÊNCIAS}

ACCENTURE. Technology Vision 2014: building cities for the citizen. Disponível em: < https://www.accenture.com/t00010101t000000_w_/au-en/_acnmedia/pdf-11/accenturetechnology-vision-2014-building-cities.pdf>. Acesso em: 30 set. 2020.

\section{AIETA, V. S. CIDADES INTELIGENTES: UMA PROPOSTA DE INCLUSÃO DOS} CIDADÃOS RUMO À IDEIA DE "CIDADE HUMANA". Revista de Direito da Cidade, v. 8, n. 4, p. 1622- 1643, 2016. Disponível em: < https://www.epublicacoes.uerj.br/index.php/rdc/article/viewFile/25427/19155>. Acesso em: 30 set. 2020.

CUNHA, M.; PRZEYBILOVICZ, E.; MACAYA, J. F. M.; SANTOS, F. B. P. D. et al. Smart Cities: Transformação digital de cidades. 1ed. São Paulo: Programa Gestão Pública e Cidadania - PGPC, 2016. Disponível em: <

http://bibliotecadigital.fgv.br/dspace/handle/10438/18386>. Acesso em: 30 set. 2020.

DAMERI, R.; COCCHIA, A. Smart city digital city: Twenty years of terminology evolution. $\mathbf{X}$ Conference of the Italian Chapter of AIS, ITAIS, Università Commerciale Luigi Bocconi, Milan (Italy), p. 1-8, 2013.

\section{ELLEN MACARTHUR FOUNDATION., Shenzhen Transição Para Um Sistema De} Mobilidade Elétrica Na Cidade: Desenvolver mobilidade elétrica no sistema público de ônibus e além. Março de 2019. Disponível em: < https://www.ellenmacarthurfoundation.org/assets/downloads/Shenzhen.pdf $>$. Acesso em: 30 set. 2020.

\section{EMBAIXADA DA REPÚBLICA POPULAR DA CHINA NO BRASIL. Embaixador Li} Jinzhang: 13 Plano Quinquenal proporciona oportunidades históricas à cooperação sino-latino-americana. Disponível em:< http://br.china-embassy.org/>. Acesso em: 02 out. 2020.

FERREIRA, D. L. L.; GUABIROBA, R. P.; DE PAIVA, D. M.; DE ALMEIDA, G. M. O investimento do governo chinês em energia limpa e projetos ambientais. In: IX Congresso Brasileiro de Planejamento Energético- CBPE, Florianópolis, 2014.

GRAY, A. Shenzhen just made all its buses electric, and taxis are next. 02 nov. 2018. Disponível em:< https://www.weforum.org/agenda/2018/11/shenzhen-just-made-all-itsbuses-electric-and-taxis-are-next>. Acesso em: 02 out. 2020.

LIN, Y.; ZHANG, K.; SHEN, Z. J. M.; MIAO, L.Charging Network Planning for Electric Bus Cities: A Case Study of Shenzhen, China. Sustainability, p. 1-27, 2019. Disponível em< https://www.mdpi.com/2071-1050/11/17/4713/htm>. Acesso em: 30 set. 2020. doi:10.3390/su11174713

LONGFELLOW, T. City Profile: Shenzhen. 8 mar. 2017. E-bi. Ideas. Delivered. Disponível em:< https://e-bi.com/2017/03/08/city-profile-shenzhen/>. Acesso em 30 set. 2020.

XUE, L.; ZHOU, W. How did Shenzhen, China build world's largest electric bus fleet? World Resources Institute. 04 apr. 2018. Disponível em: < https://www.wri.org/blog/2018/04/howdid-shenzhen-china-build-world-s-largest-electric-bus-fleet>. Acesso em 30 set. 2010.

MOBILIZE BRASIL. Mobilidade urbana sustentável. Shenzhen, na China, a 1aㅡ cidade a ter $100 \%$ dos ônibus e táxis elétricos. 2018. Disponível em:< https://www.mobilize.org.br/noticias/11368/shenzhen-na-china-a-1a-cidade-a-ter-100-dosonibus-e-taxis-eletricos.html>. Acesso em: 02 out. 2020.

NG. M. K. City profile Shenzhen. Cities, v. 20, n. 6, p. 429-441, 2003. 
Planet smart city. China possui o maior número de cidades inteligentes. 28 nov. 2018. Disponível em: <https://www.planetsmartcity.com.br/china-possui-o-maior-numero-deprojetos-de-cidades-inteligentes/>. Acesso em: 30 set. 2020.

PNUMA. Renewables In Cities 2019 Global Status Report. Disponível em: < https://www.ren21.net/wp-content/uploads/2019/05/REC-2019-GSR_Full_Report_web.pdf>. Acesso em: 30 set. 2020.

ROSSATTO, L. Cidades Inteligentes: de onde vieram e para onde vão? Outra cidade, 3 de agosto de 2015. Disponível em:< https://outracidade.com.br/cidades-inteligentes-de-ondevieram-e-para-onde-vao/>. Acesso em: 30 set. 2020.

ZOTIN, M. Z. O Papel da China na transição energética global: estado, indústria e recursos. 2018. Dissertação (mestrado em Planejamento Energético) - Instituto Alberto Luiz Coimbra de Pós-graduação e Pesquisa de Engenharia (COPPE) da Universidade Federal do Rio de Janeiro, Rio de Janeiro.

\section{NOTAS DE AUTOR}

\section{CONTRIBUIÇÃO DE AUTORIA}

Verônica Nascimento Brito Antunes - Concepção, coleta dos dados, análise de dados e elaboração do manuscrito.

Jacilene dos Santos Silva - Coleta de dados e contribuição na elaboração do manuscrito.

Camila do Carmo Hermida - Revisão e aprovação da versão final do trabalho.

FINANCIAMENTO

Não se aplica.

\section{CONSENTIMENTO DE USO DE IMAGEM}

Não se aplica.

APROVAÇÃO DE COMITÊ DE ÉTICA EM PESQUISA

Não se aplica.

\section{CONFLITO DE INTERESSES}

Não se aplica.

\section{LICENÇA DE USO}

Este artigo está licenciado sob a Licença Creative Commons CC-BY. Com essa licença você pode compartilhar, adaptar, criar para qualquer fim, desde que atribua a autoria da obra.

\section{HISTÓRICO}

Recebido em: 01-10-2020

Aprovado em: 01-11-2020 